\title{
EFEITO DE DIFERENTES EXCIPIENTES E DE DESINTEGRANTE NA FORMULAÇÃO DE PELLETS DE NIFEDIPINO PRODUZIDOS POR EXTRUSÃO-ESFERONIZAÇÃO
}

\author{
L. F. G. de SOUZA ${ }^{1}$, M. NITZ ${ }^{1}$, F. GARJULLI ${ }^{1}$ e O. P. TARANTO ${ }^{2}$ \\ ${ }^{1}$ Instituto Mauá de Tecnologia (IMT), Departamento de Engenharia Química e Engenharia de \\ Alimentos \\ ${ }^{2}$ Universidade Estadual de Campinas (UNICAMP), Departamento de Engenharia Química \\ E-mail para contato: luciane.souza@maua.br
}

RESUMO - O nifedipino (NF) é uma droga praticamente insolúvel em água, com solubilidade menor que $10 \mu \mathrm{g} / \mathrm{mL}$, de baixa e irregular biodisponibilidade depois da administração oral. É o vaso dilatador mais amplamente utilizado do grupo de derivados de diidropiridina. Com o objetivo de melhorar a dissolução in vitro do NF, nesse trabalho microgrânulos do ativo foram produzidos por extrusão-esferonização utilizando-se em sua formulação diferentes teores do desagregante croscarmelose sódica (CS) e celulose microcristalina (MCC) como excipiente principal. Microgrânulos contendo lactose (L) como excipiente base também foram produzidos a fim de comparar o perfil de liberação do ativo com o perfil de pellets a base de MCC. Os testes de dissolução mostraram que quanto maior o teor de CS no pellet mais rápida é a liberação do NF no meio de dissolução. Microgrânulos com teores acima de $22 \%$ de CS apresentaram liberação total do ativo em 12 horas e seus perfis de liberação se mostraram superiores a de outros trabalhos que fizeram uso de dispersões sólidas ou de partículas micronizadas do ativo. Os pellets produzidos com L como excipiente base apresentaram $90 \%$ de liberação do ativo na primeira hora, enquanto que os microgrânulos produzidos com MCC apresentaram apenas $16 \%$. Pellets de NF com matriz de liberação prolongada foram produzidos e apresentaram frações de ativo liberada dentro do estabelecido na USP.

\section{INTRODUÇÃO}

O nifedipino é um ativo pouco solúvel em água e amplamente utilizado como agente bloqueador do cálcio, cuja eficácia e tolerabilidade têm sido demonstradas em inúmeros estudos (O’Connor e Schwartz, 1985). É um princípio ativo muito utilizado no tratamento de angina e hipertensão. A farmacocinética e farmacodinâmica do nifedipino tem sido caracterizada utilizando diversas formulações de nifedipino destinadas à utilização oral bem como parenteral. Tem sido demonstrado que o rápido aumento na concentração plasmática de nifedipino resulta em uma aceleração no ritmo cardíaco e efeitos colaterais (Walley et al., 1987; Soons et al., 1992; Total, 2004). Assim, formulações de liberação modificada de nifedipino são as primeiras escolhas terapêuticas. 


\section{9 a 22 de outubro de 2014 \\ Florianópolis/SC}

Os pellets são produzidos por meio de um processo de granulação seguido de extrusão e esferonização (Santos et al., 2004; Campbell, 1999). O princípio ativo pode estar incorporado à mistura de pós, distribuído uniformemente pela massa, ou ser depositado na superfície de um grânulo inerte por um processo de recobrimento, como nos estudos de Nikowitz et al. (2011) e Tang et al. (2004).

A celulose microcristalina é considerada um componente essencial para o sucesso da extrusãoesferonização, o que se deve à modificação que provoca nas propriedades reológicas da massa úmida (Gandi et al., 1999). Os pellets de ativos pouco solúveis em água contendo como excipiente celulose microcristalina e produzidos por extrusão-esferonização apresentam lenta dissolução devido à contração pronunciada dos microgrânulos durante o período de secagem, levando a redução na porosidade, dificultando, assim, a penetração do meio de dissolução no pellet (Souto et al., 2005). A lenta taxa de dissolução das drogas pouco hidrossolúveis de microgrânulos de celulose microcristalina preparados por extrusão - esferonização vem sendo amplamente documentada (Zhang et al., 1990).

O presente trabalho avalia o efeito do desagregante croscarmelose sódica em microgrânulos de nifedipino produzidos por extrusão-esferonização, contendo a celulose microcristalina e lactose monohidratada como excipientes base. Diferentes teores de desagregantes foram incorporados nos microgrânulos a fim de verificar a influência da croscarmelose sódica no perfil de dissolução obtido. Pellets de nifedipino com matriz de liberação prolongada dentro dos parâmetros farmacopeicos (USP XXXII, 2009) foram desenvolvidos.

\section{MATERIAIS E MÉTODOS}

\subsection{Excipientes e equipamentos}

Nifedipino foi fabricado por Amishi Labs (Índia). A celulose microscristalina PH-101 (MCC) utilizada foi comercializada e fabricada por Mingtai Chemical (Taiwan). Croscarmelose sódica foi comercializada e fabricada Amishi Labs (Índia). Polietileno glicol (PEG 4000) foi comercializado e fabricado por Oxiteno (Brasil). Polivinil pirrolidona (PVP - K30) foi comercializado e fabricado por Nachang Industrial (China). Methocel, hidropropilmetilcelulose, foi comercializado e fabricado por Colorcon (Dartford, Kent, Inglaterra). Lactose foi comercializada por Valdequímica Produtos Químicos Ltda (Brasil). A mistura e granulação foram realizadas em batedeira planetária (Arno, modelo Ciranda Chrome Automatic, Brasil). Para a extrusão da massa, utilizou-se um extrusor do tipo rolos, marca Zelus, modelo EX-01. Para a esferonização na etapa seguinte à da extrusão, utilizou-se o esferonizador da marca Zelus, modelo ES-015. Para a secagem dos pellets utilizou-se estufa com circulação forçada de ar e controle de temperatura marca Nova Ética, modelo 420-4D. Para classificação granulométrica dos pellets foi utilizado conjunto de peneiras com telas de aço com aberturas entre $0,425 \mathrm{~mm}$ e $1,40 \mathrm{~mm}$. Utilizou-se vibrador de peneiras da marca Abronzinox. Para quantificação do ativo no teste de dissolução e no procedimento de determinação de teor, foi utilizado um Espectrofotômetro UV/VIS 800 XI FEMTO. Nos testes de dissolução, utilizou-se um dissolutor com 6 cubas de 900 mL, com controle de temperatura e rotação, modelo 299.

\subsection{Preparação dos pellets}


Todas as formulações foram preparadas com $15 \%$ de PEG4000, $1 \%$ de methocel, $4 \%$ de PVPK30 e 25\% de nifedipino. Os teores de croscarmelose sódica nos pellets a base de celulose microcristalina utilizados nas misturas dos pós variaram de acordo com o que consta na Tabela 1. Os pellets produzidos com lactose como excipiente base foram preparados com $8 \%$ de croscarmelose e $47 \%$ de lactose na mistura de pós. Solução de $1 \%$ de methocel foi utilizada na preparação da massa úmida em todas as formulações.

Tabela 1 - Teores de excipientes utilizados na mistura dos pós

\begin{tabular}{lccccc}
\hline & F1 (\%) & F2 (\%) & F3 (\%) & F4 (\%) & F5 (\%) \\
\hline Desagregante & 8 & 15 & 18 & 22 & 30 \\
MCC & 47 & 40 & 37 & 33 & 25 \\
\hline
\end{tabular}

\subsection{Testes de dissolução}

Para simular o perfil de dissolução dos microgrânulos no estômago, aproximadamente $50 \mathrm{mg}$ de pellets, na faixa granulométrica de $0,71 \mathrm{a} 1,40 \mathrm{~mm}$, foram pesados em balança analítica e transferidos para o aparato cesto do dissolutor. Os microgrânulos foram imersos em cubas contendo $900 \mathrm{~mL}$ de fluido gástrico sem enzima contendo $0,5 \%$ de sulfato lauril de sódio - $\mathrm{pH} 1,2$. O aparato contendo os pellets foi mantido em uma rotação de $100 \mathrm{rpm}$ e a temperatura das cubas foi mantida em $37^{\circ} \mathrm{C}$.

\section{RESULTADOS E DISCUSSÕES}

\subsection{Análise granulométrica e morfológica do ativo}

A faixa granulométrica de nifedipino observada na Figura 1 é de 0,5 a $70 \mu \mathrm{m}$, sendo que a maioria das partículas está compreendida na faixa granulométrica de 3 a $40 \mu \mathrm{m}$. O diâmetro médio das partículas de nifedipino incorporadas em todas as formulações de pellets estudadas neste projeto é de $12,15 \pm 0,09 \mu \mathrm{m}$. Além disso, os valores de $\mathrm{D}(\mathrm{v} ; 0,9)$ indicam que $90 \%$ da amostra analisada possui, em média, tamanho de partícula inferior a $25,40 \pm 0,32 \mu \mathrm{m}$.

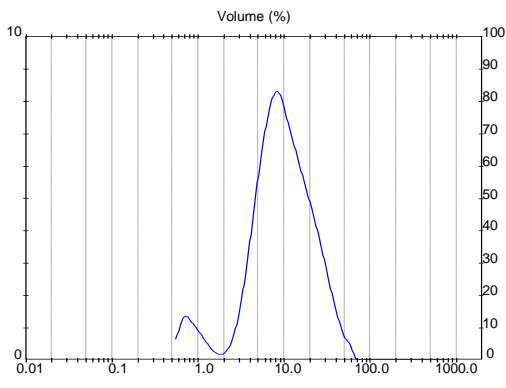

Diâmetro da partícula $(\mu \mathrm{m})$

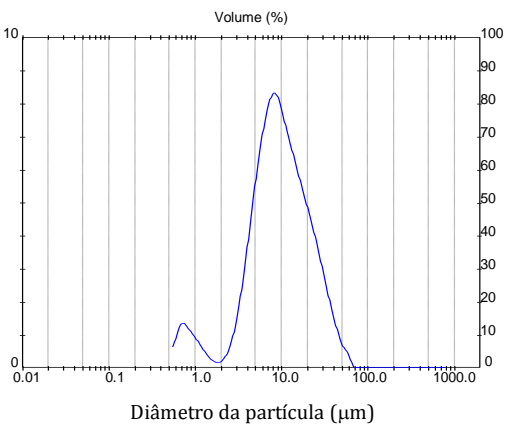

Diâmetro da partícula $(\mu \mathrm{m})$

Figura 1 - Distribuição granulométrica das partículas de NF utilizadas na produção dos pellets 
A análise das imagens não permite que se estabeleçam medidas geométricas estatisticamente significativas. Porém, pela escala presente na Figura 2, pode-se afirmar que a ordem de grandeza do tamanho das partículas está de acordo com as medidas de distribuição granulométrica apresentadas na Figura 1. A micrografia realizada no MEV também mostra que as partículas não possuem forma cristalina definida, além de algumas delas apresentarem-se aglomeradas.
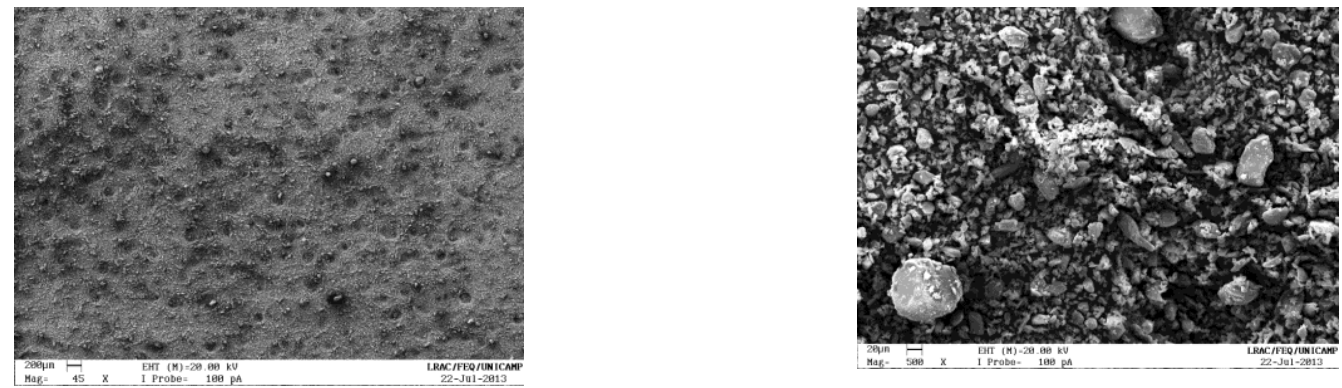

Figura 2 - Micrografias eletrônicas de varredura do nifedipino

\subsection{Efeito da croscarmelose sódica e dos excipientes base nos pellets de nifedipino}

A maioria dos microgrânulos com formulação apresentada na Tabela 1, cerca de 70\%, apresentaram granulometria na faixa de 0,70 e $1,18 \mathrm{~mm}$ em todas as formulações testadas. A Figura 3 (a) ilustra a distribuição granulométrica dos pellets, com $8 \%$ de desintegrante, à base de lactose e, 15 e $22 \%$, à base de MCC. A Figura 3 (b) ilustra os perfis de dissolução do NF nos microgrânulos com MCC como excipiente principal. Foram testadas formulações com teores de desintegrante entre $8 \%$ e $30 \%$. Observa-se que a quantidade da droga liberada no meio de dissolução é acelerada pelo aumento do teor de desagregante presente nos pellets. Microgrânulos com 8, 15 e 18\% de CS apresentaram um perfil de liberação muito lento. Depois de 12 horas de dissolução, a liberação foi de apenas 28,50 e $60 \%$. A grande retenção de ativo nesses casos, decorridas 12 horas de dissolução, mostra que a presença de desintegrante não é suficiente para proporcionar dissolução total do fármaco. Entretanto, as formulações com teores mais elevados de desagregante apresentaram praticamente liberação de todo o ativo contido no microgrânulo, embora de forma lenta. Com $22 \%$ de croscarmelose, houve liberação de $58 \%$ da droga na primeira hora e $95 \%$ depois de 12 horas. Com $30 \%$ de croscarmelose, a liberação foi de $75 \%$ na primeira hora e $95 \%$ em 5 horas.
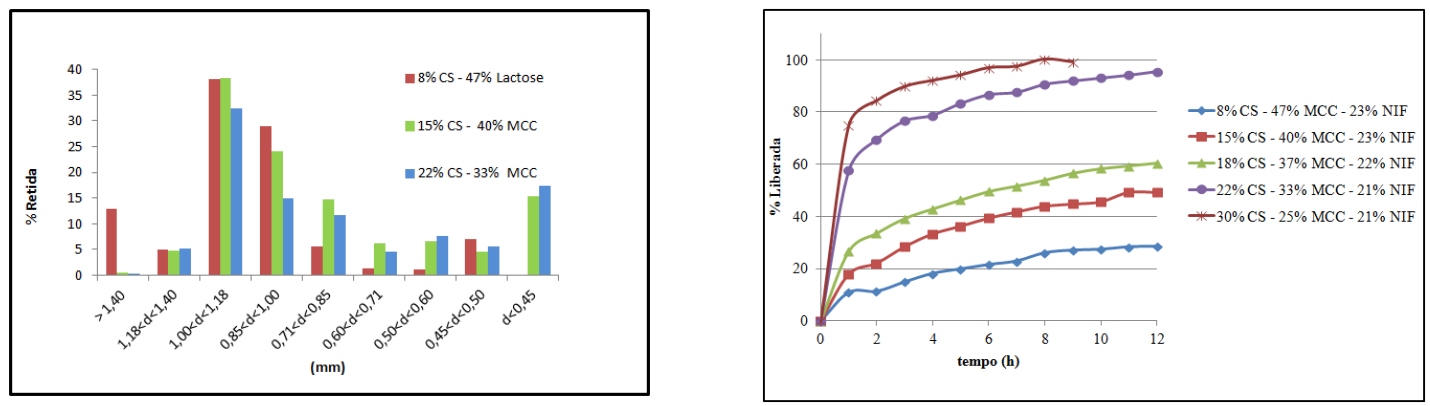

Figura 3 - (a) Distribuição granulométrica de microgrânulos base lactose e MCC, (b) Perfis de liberação do NF para diferentes teores de desintegrante CS em pellets a base de MCC 


\section{9 a 22 de outubro de 2014 \\ Florianópolis/SC}

A Figura 4 ilustra os perfis de dissolução do NF nos microgrânulos com mesma quantidade de desintegrante e excipientes bases distintos. A liberação do ativo em pellets com lactose na primeira hora foi de aproximadamente $90 \%$, enquanto que em pellets com MCC foi de apenas $16 \%$. Esse resultado corrobora o trabalho de Souto et al (2005) no que diz respeito à lenta dissolução de ativos pouco solúveis de pellets preparados por extrusão-esferonização utilizando MCC como excipiente base. A superfície e forma dos pellets base lactose e MCC foram observadas pelo MEV. Os microgrânulos com excipiente base MCC apresentaram formato mais esférico que os produzidos com lactose (Figura 5). De acordo com imagens do MEV, superfícies mais lisas foram encontradas em pellets base MCC com menor teor de CS (Figura $5 \mathrm{~b}$ ). Estrutura mais porosa foi observada em pellets contendo lactose e em pellets de MCC com maior teor de CS (Figura 5 a - c). Segundo Sun (2005), a presença de poros grandes facilita a rápida penetração da água no interior do pellet com a posterior ruptura das ligações, seguida da desintegração do microgrânulo, o que nesse trabalho foi confirmado pelo perfil de liberação imediato obtido com microgrânulos à base de lactose e o lento perfil de dissolução em microgrânulos a base de MCC.

Para uma liberação controlada em pellets com lactose, faz-se necessário o recobrimento polimérico de liberação modificada, já para uma liberação imediata a formulação testada é adequada. Nenhum dos perfis obtidos em microgrânulos à base de MCC é adequado para uma formulação de liberação controlada. Para teores de croscarmelose até $18 \%$, a liberação é muito lenta e há retenção de ativo na fórmula. Apenas $28 \%, 38 \%$ e $60 \%$ do ativo são liberados em 12 horas para teores de croscarmelose de $8 \%, 15 \%$ e $18 \%$, respectivamente. Por outro lado, quando o teor de croscarmelose é maior ou igual a 22\%, embora se consiga liberação de $90 \%$ do ativo em até 8 horas, a liberação inicial é muito rápida. Em 1 hora de dissolução, $58 \%$ e $75 \%$ de NF são liberados nas formulações com $22 \%$ e $30 \%$ de croscarmelose, respectivamente. A utilização da croscarmelose em pellets à base de MCC mostrou-se eficaz para superar o problema da pouca solubilidade do ativo, que dificulta o desenvolvimento de formas de liberação controlada. O perfil de dissolução de pellets de liberação prolongada pode agora ser ajustado com a incorporação de lactose, MCC e CS na formulação dos microgrânulos, de forma que a matriz do pellet adquira um perfil de liberação prolongada.

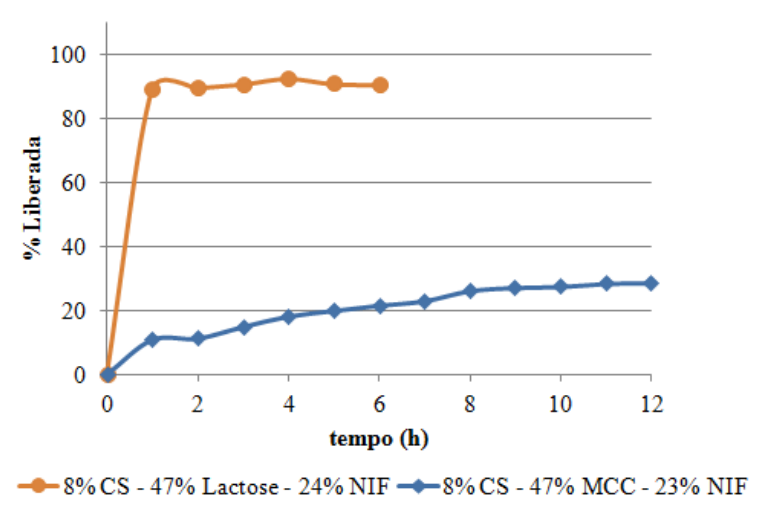

Figura 4 - Perfis de liberação do NF em pellets com excipiente base distintos 
(a) $8 \% \mathrm{CS}$ - Lactose

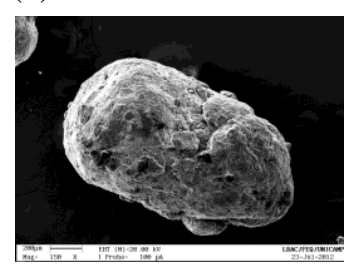

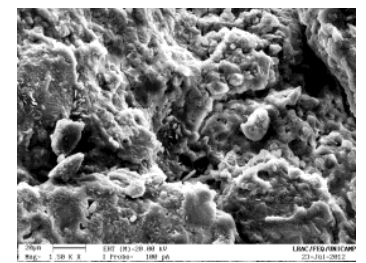

(c) $22 \% \mathrm{CS}-\mathrm{MCC}$ (b) $8 \% \mathrm{CS}-\mathrm{MCC}$
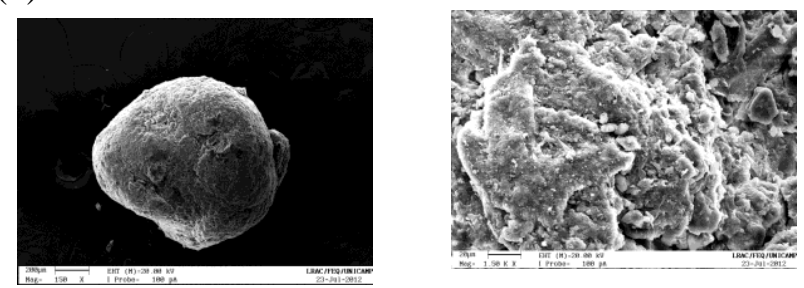
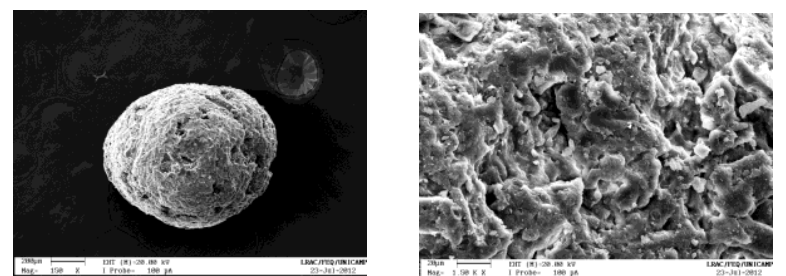

Figura 5 - Micrografias de pellets base lactose e MCC com diferentes teores de desagregante.

\subsection{Pellets com matriz de liberação prolongada}

A incorporação dos excipientes na formulação dos microgrânulos de nifedipino (Tabela 2) resultou em pellets com matriz de liberação prolongada e perfil de dissolução dentro do estabelecido na farmacopeia americana (USP XXXII, 2009), como pode ser visto na Figura 6 e Tabela 3. Como estes resultados foram obtidos de bateladas distintas, eles comprovam a reprodutibilidade do processo. De acordo com as imagens do MEV (Figura 7), observa-se que os microgrânulos possuem formato próximo de uma esfera, entretanto, em alguns deles, é possível identificar algumas frações de aglomerados. Na Figura 7 (b), observa-se uma superfície com aspecto rugoso parecida com a observada em pellets com lactose e alto teor de croscarmelose sódica e não tão lisa quanto à superfície de microgrânulos obtida apenas com MCC como excipiente base. A presença de poros maiores é devida à incorporação da lactose monohidratada na formulação dos microgrânulos e à presença de uma quantidade suficiente de desintegrante croscarmelose sódica, responsável por provocar o intumescimento do microgrânulo. Segundo SUN (2005), a presença de poros maiores facilita a rápida penetração da água no interior do pellet com a posterior ruptura das ligações, seguida da desintegração do microgrânulo.

Tabela 2 - Proporção dos excipientes e ativo utilizados na obtenção dos pellets de liberação prolongada

\begin{tabular}{cc}
\hline Matéria-prima & \% Sólidos \\
\hline PEG 4000 & 15,0 \\
MCC 101 & 26,5 \\
Lactose & 26,5 \\
Croscarmelose sódica & 2,0 \\
Methocel & 1,0 \\
PVP K30 & 4,0 \\
Nifedipino & 25,0 \\
\hline
\end{tabular}


Tabela 3 - Valores absolutos das médias de fração de nifedipino liberada nos testes de dissolução in vitro dos pellets produzidos e as faixas de valores de fração liberada estabelecidos na farmacopeia americana

\begin{tabular}{ccc}
\hline Tempo (h) & $\begin{array}{c}\text { Fração liberada }(\%)- \\
\text { experimental }\end{array}$ & $\begin{array}{c}\text { Fração liberada (\%) - } \\
\text { Farmacopéia americana }\end{array}$ \\
\hline 1 & $27,1 \pm 2,5$ & $10-35$ \\
4 & $56,7 \pm 2,4$ & $40-67$ \\
12 & $80,5 \pm 1,6$ & Não menos que 80 \\
\hline
\end{tabular}

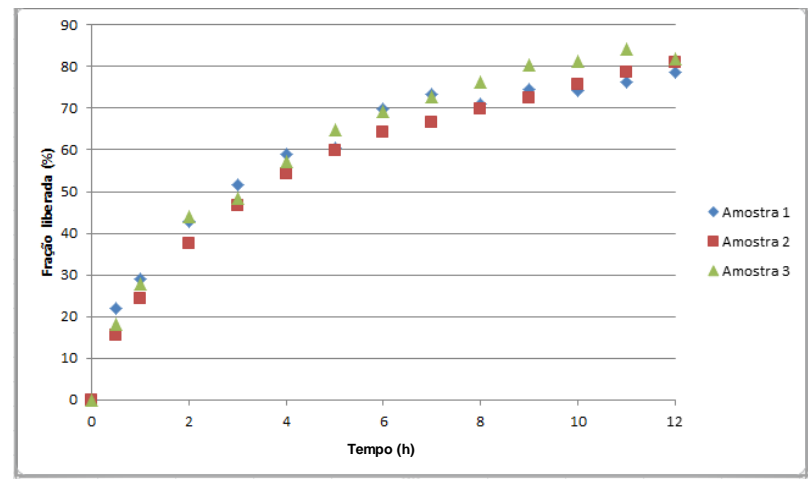

Figura 6 - Perfil de liberação de nifedipino em pellets com MCC e lactose como excipientes base

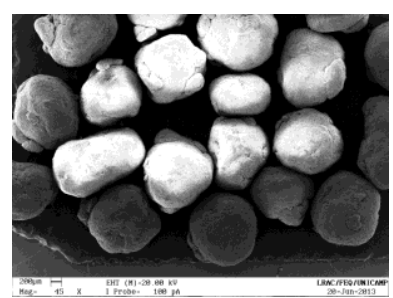

(a)

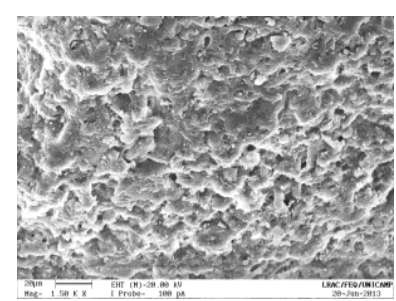

(b)

Figura 7 - Microscopia eletrônica de varredura de pellets de nifedipino com matriz de liberação prolongada

\section{CONCLUSÕES}

O desintegrante croscarmelose sódica em pellets de nifedipino à base de celulose microcristalina influencia positivamente a taxa de dissolução, acelerando o perfil de liberação da droga. Com teores de croscarmelose acima de $22 \%$, conseguiu-se liberação total do ativo em até 12 horas. A presença da croscarmelose sódica promove um aumento na porosidade dos pellets, que, ao entrar em contato com o meio de dissolução, aumenta a taxa de dissolução da droga. A liberação do ativo em pellets à base de MCC retarda a liberação do ativo quando comparada com a liberação em pellets à base de lactose, para uma mesma quantidade de desintegrante. O perfil de liberação do ativo em pellets à base de celulose microcristalina foi controlado variando-se a proporção celulose microcristalina : croscarmelose sódica : lactose monohidratada na formulação dos pellets, juntamente 
com a utilização de polímeros controladores da liberação incorporados na matriz dos microgrânulos. Pellets de nifedipino com matriz de liberação prolongada apresentaram valores de fração de ativo liberada dentro dos valores estabelecidos pela Farmacopéia Americana USP XXXII.

\section{REFERÊNCIAS}

CAMPBELL, R.J., SACKETT G.L. Film Coating. In: Coating - Drug Manufacturing Technology Series. USA: Interpharm CRC, 1999, 348 p.

GANDI R; KAUL C.L., PANCHAGNULA R. Extrusion and spheronization in the development of oral controlled-release dosage forms. Pharm Sci Technol Today, v. 2, p. 160-170, 1999.

NIKOWITZ, K., KÁSA, P.J., HÓDI, K.P., REGDON, G.J. Study of the preparation of a multiparticulate drug delivery system with a layering technique. Powder Technol, v. 205, p. 155-159, 2011.

O'CONNOR, R. E., SCHWARTZ, J. B. Spheronization II. Drug release from drug-diluent mixtures. Drug Development and Industrial Pharmacy, v.11, p. 1837-1857, 1985.

SANTOS, H. M. M., VEIGA, F. J. B., PINA, M. E. T., SOUSA, J. J. M. S. Obtenção de pellets por extrusão e esferonização farmacêutica - Parte I - Avaliação das variáveis tecnológicas e de formulação. Ver. Bras, Cienc. Farm Braz J Pharm Sci, v. 40, p. 455-470, 2004.

SOONS, P.A., SCHOEMAKER, H. C., COHEN, A. F., BREIMER, D. D. Intraindividual variability in nifedipine pharmacokinetics and effects in healthy subjects. Journal of Clinical.Pharmacology, v.32, p. 324-331, 1992.

SOUTO, C., RODRÍGUEZ, A., PARAJES, S., PACHECO, R. A comparative study of the utility of two superdisintegrants in microcrystaline cellulose pellets prepared by extrusion-spheronization. Eur. J. Pharm. Biopharm, v. 61, p. 94-99, 2005.

SUN, C.C. Critical roles of porosity in tableting properties characterization and solids formulation development. American Pharmaceutical Review 8, p. 102-107, 2005.

TANG, X., TIAN, X., CI, L. Preparation and evaluation of $\mathrm{pH}$-dependent gradient-release pellets for TCM . Drug Development and Industrial Pharmacy, v. 30, p. 1079-1087, 2004.

TOTAL, C. B. Formulation dependent pharmacokinetics - does the dosage form matter for nifedipine? J. Cardiovasc. Pharmacol, v. 44, p. 82-86, 2004.

USP XXXII. The United States Pharmacopeia, NF 27, 3rd ed, p. 3083-3089, 2009.

WALlEY, T. J.,HEAGERT, A. M., WOODS, K. L., BING, R. F., POHL, J. E., BARNETT, D. B., Pharmacokinetics and pharmacodynamics of nifedipino infusion in normal volunteers. Br. J. Clin. Pharmacol, v. 23, p. 693-701, 1987.

ZHANG, G., SCHWARTZ, J.B., SCHNAARE, R.L. Effect of spheronization technique on drug release from uncoated beads. Drug Development and Industrial Pharmacy, v. 16, p. 1171-1184, 1990. 